\title{
¿Habría que rehacer la semiótica?
}

\author{
Eric Landowski \\ Centre National de la Recherche Scientifique (CNRS, Francia)
}

Recibido: 15/11/2011

Aceptado: 12/12/2011

\begin{abstract}
Resumen: En la vida cotidiana, usualmente buscamos signos en la superficie del mundo, como si fuera un texto. Pero también ocurre, en ausencia de signos particulares que puedan referir a algunas significaciones previamente categorizadas, que tenemos la sensación de estar en presencia de elementos que hacen sentido. Rostros, imágenes, música, incluso objetos, como un auto, funcionan (parcialmente) de esta manera: sensitivamente capturamos lo que significan para nosotros, antes que leerlos cognitivamente como signos. La semiótica debe desarrollar herramientas para dar cuenta para estos dos modos de sentido. El presente ensayo reconsidera críticamente, con vistas a estos objetivos, las nociones básicas de narratividad y discursividad, y propone un modelo articulando diferentes regímenes de significación en juego en la interacción humana.

Palabras clave: existencial / sensible / estésico / hacer sentido / figurativo / plástico / narratividad / experiencia / interacción / programación / manipulación / ajuste / asentir.
\end{abstract}

\section{Re-making Semiotics?}

Summary: In daily life, we are often searching for signs at the surface of the world, as if it were a text. But it also happens, in the absence of any particular signs which would convey some previously categorized significations, that we have the feeling of being in the presence of elements that make sense. Faces, images, music, even objects as a car function (partly) this way: we sensitively grasp what they mean for us, rather than we cognitively read them as signs. Semiotics should develop tools in order to account for both these modes of meaning. The present essay reconsiders critically, with this scope, the basic semiotic notions of narrativity and discursivity, and proposes a model articulating different regimes of meaning at play in human interaction.

Keywords: existential / sensitive / aesthesic / make sense / figurative / plastic / narrativity / experience / interaction / programation / manipulation / adjustment / assent. 


\section{De la vivencia al enunciado y retorno}

- Ha llegado el tiempo de una semiótica existencial? Esta problemática la venimos considerando desde hace algunos años, planteada como conclusión de Pasiones sin nombre, sin haber tenido conocimiento hasta entonces de trabajos emprendidos en torno a esa idea, excepto los avanzados, aunque desde una óptica diferente, por Eero Tarasti (Tarasti 2000, 2009; Landowski 2004: 293-305). Aunque no haya en eso más que una coincidencia, tal orientación no haría otra cosa sino reanudar la ambición que animó al comienzo la corriente semiótica de la que nos reclamamos seguidores. Esa es, en todo caso, nuestra convicción, a riesgo de sorprender tal vez a aquellos que ven la semiótica "greimasiana" desde el exterior y de chocar con aquellos hábitos de pensamiento preferidos por algunos de los que la practican.

A los ojos de los semióticos de estricta obediencia estructural, para elaborar un discurso sensato a propósito del sentido, no existe, en efecto, más que una manera de proceder, que consiste en analizar las producciones manifiestas a través de las cuales el sentido se deja aprehender, comenzando por esas "manifestaciones" significantes por excelencia que son los textos.

Cuantas mayores garantías de cientificidad parece ofrecer esa opción, más aventurado sería, y para los más ortodoxos, hasta ocioso, interrogarse acerca de las implicaciones existencia- les de la experiencia totalmente "subjetiva" que vivimos cuando experimentamos de manera impresiva la presencia, a nuestro alrededor, de un mundo que unas veces parece hacer sentido, otras veces, no, sin que podamos decir con precisión por qué ni cómo. "Hacer sentido", "presencia", "impresivo", "experimentar", "vivencia"..., el empleo de tal vocabulario es todavía hoy objeto de fuertes resistencias, a pesar de los esfuerzos desplegados desde hace largos años por algunos investigadores para integrar esos términos al metalenguaje semiótico (Geninasca 1984, Greimas 1987, Landowski 1988, Hénault 1994, Parret 2001). Eso, seguramente, porque ese vocabulario no parece, de entrada, compatible con los procedimientos del análisis textual. Y es cierto que si en un primer momento Propp, Greimas y algunos otros no hubieran decidido analizar diversos tipos de textos -folclóricos, mitológicos o literarios- no solo independientemente de su inserción en la cultura de la que cada uno provenía, o del lugar que esos objetos ocupaban en la producción de sus autores, sino también haciendo abstracción de las impresiones estéticas o de las reacciones morales que su lectura pudiera suscitar en sus lectores, no podría haberse construido ninguno de los modelos operativos con los que hoy contamos.

Eso, sin embargo, no ha dejado de tener su contrapartida. La focalización en el texto tuvo por efecto alejar a los partidarios del acercamiento estructural de otras corrientes de re- 
flexión semiótica, especialmente de la de Peirce, que apunta, como se sabe, a la construcción de una teoría de la significación considerada en su más amplia generalidad. No obstante, en Greimas, también el resorte inicial de la reflexión fue una interrogación acerca del sentido en general. En él, al comienzo, no se trataba solamente de preguntarse sobre la significación de los textos, sino del "sentido de las actividades humanas", del "sentido de la historia", o simplemente, según una expresión que le era familiar, del "sentido de la vida" (Greimas 1971: 8, Greimas y Courtés 1982, entrada: <<Narrativo (esquema->>, 2).

En Semántica estructural, su primer libro, trató de refundar la semántica para hacer de ella una teoría capaz de sobrepasar los límites de los tratamientos lexicales, lingüísticos o lógicos, entonces dominantes, y para eso, dejó de lado las precauciones epistemológicas corrientes en aquel momento y se fijó como marco de reflexión el horizonte más amplio que se podía concebir: partir de "la situación del hombre" y de aquello que constituye el rasgo primero y decisivo, a saber, el hecho de que, para cada uno de nosotros, "habitar el mundo consiste, de la mañana a la noche y de la edad prenatal hasta la muerte, en ser asaltados por las significaciones que nos solicitan por todas partes" (Greimas 1971: 12). Y a contrario, podríamos añadir, ¿sería aún "vivir" habitar un mundo reducido a la insignificancia o al sinsentido? Dicho de otro modo, de lo que realmen- te se trataba entonces era de nuestra condición existencial en cuanto seres semióticos.

Pero, al mismo tiempo, la "vocación científica" asignada al proyecto semiótico desde las primeras páginas del mismo libro (conforme con el subtítulo, Investigación de método) exigía la mayor vigilancia posible contra el riesgo de caer en un discurso impresionista o psicologizante, o de limitarse a una reflexión de tipo especulativo, que hubiera terminado en una filosofía del lenguaje entre otras. Para constituirse en teoría y en método operativo, la semiótica estructural debía concebir su objeto, como un objeto de ciencia. Eso condujo a pasar de una reflexión general referida al "sentido vivido" a una problemática del "sentido manifestado" -primera reducción- y de ahí, segunda reducción, a una analítica del texto enunciado, olvidando con ello y por largo tiempo "la vida". La semiótica se convirtió así, tal vez, en una "ciencia" -sin ninguna duda, en un método- pero desconectada de aquello que, para una disciplina consagrada a la búsqueda del sentido, es, dígase lo que se quiera, la única cuestión que vale la pena: comprender mejor cómo, en qué condiciones, por qué procedimientos nuestra presencia en el mundo llega a tener sentido.

Lo que nosotros nos proponemos es una vuelta a esa interrogación primera, porque creemos que los dos términos de la oposición implícitamente admitida - la ciencia por un lado, la 
vida por otro- no son irreconciliables, sino que, por el contrario, la dimensión existencial del sentido puede ser objeto, a la vez como tema de reflexión y como materia que conceptualizar, de un acercamiento riguroso, en términos semióticamente articulados. Aunque tal punto de vista tiene connotaciones más filosóficas que aquello de lo que se preocupan la mayoría de los semióticos, es precisamente en cuanto semióticos y no en cuanto filósofos como nosotros lo concebimos y como pretendemos justificarlo. El proceder que eso exige de nuestra parte en el plano conceptual no está impuesto por ningún imperativo, ni filosófico ni de otra naturaleza, exterior a la semiótica misma, sino que se impone como una exigencia inseparable del oficio de semiótico tal como nosotros lo entendemos. Ante todo, ¿para qué "hacer semiótica"? ¿-por qué interrogarse sobre el sentido- si eso no fuera a ayudar a plantear para uno mismo la cuestión del "sentido de la vida", de la propia vida? Y más técnicamente segundo resorte de nuestro proceder-, de la práctica misma de los modelos semióticos, así como del examen crítico que esa práctica lleva inevitablemente a realizar, deriva la necesidad y la posibilidad, en nuestra opinión, de reabrir el campo de la reflexión y de los análisis.

No hay en eso ni deseo de provocación ni la pretensión absurda de invalidar los principios de la disciplina dentro de la cual nosotros mismos nos situamos. Se trata, por el contrario, de ampliar su alcance, de revivificar su práctica y de enriquecer sus desafíos. La prueba está en que la renovación que proponemos de ninguna manera conduce a desdeñar los resultados de las investigaciones llevadas a cabo durante los tres o cuatro últimos decenios sobre las formas de la textualidad. Lejos de desconocer su utilidad, vemos en ellos una adquisición indispensable que debería precisamente permitir, con algunas ligeras modificaciones y con otros pocos complementos, reformular hoy en día la cuestión existencial originaria.

\section{State of the art ${ }^{1}$}

Pero volvamos al gesto inicial de Greimas, ${ }^{2}$ que consistió en darse por punto de partida [de su reflexión semiótica] nuestra condición existencial misma, "la situación del hombre" considerada como una totalidad sin exteriores, dentro de la cual, por consiguiente, el autor -sujeto enunciante

1 En inglés en el original [N. del T.].

2 Recientemente se han publicado las tesis de grado de A. J. Greimas y otros "escritos de juventud" con el título de La mode en 1830: Langage et société (Greimas 2000). 
y, en principio, cognoscente, el semiótico- se encuentra también encerrado, como todo el mundo. ¡Desde esa totalidad, Greimas pretende fundar una ciencia! Verdadera aporía, porque si el universo semántico se identifica con el mundo de la vida, en cuyo interior estamos todos "definitivamente encerrados" (Greimas 1971: 180), y si, además, una teoría semántica no puede concebirse más que como una descripción de orden metalingüístico, jerárquicamente distinta de su lenguaje-objeto, no se ve cómo podría tratarse semánticamente el universo englobante que uno se ha dado por objeto, reconociéndose a sí mismo contenido en él. Si ese universo nos incluye, no podremos aprehenderlo desde fuera o "desde más arriba" como lo prescribe el prefijo de meta-lenguaje. Pero entonces Greimas inventa una solución genial.

\section{Avatares y promesas de una invención}

"Lo mejor que podemos hacer", escribe, ante esta "situación" insuperable -por el hecho de que nosotros pertenecemos al mismo universo del sentido que nos proponemos analizar-, "es tomar conciencia de la visión del mundo que ahí se encuentra implicada, a la vez como significación y como condición de esa significación". En otros términos, ya que el universo significante no es objetivable en cuanto tal, desde el exterior y a distancia, la única posibilidad que se nos ofrece es la de analizarlo "desde el interior" haciendo aparecer aquello que "allí se encuentra implicado": cierta "visión del mundo".

Hay que subrayarlo: esa «visión» no consiste en una proyección de contenidos que darían al mundo percibido una coloración determinada, romántica o apocalíptica, por ejemplo. Se trata más bien de una rejilla de lectura de carácter estructural, de un principio de organización de alcance general, en función del cual el mundo adquiere forma -se deja segmentar y articular$\mathrm{y}$, en consecuencia, hace sentido. La manera específica como esa rejilla estructura nuestra visión del mundo y la hace aparecer ante nosotros en forma de un "universo significante" consiste, dice Greimas, en hacérnoslo ver como un "pequeño espectáculo" susceptible de reproducirse indefinidamente, en "millones de ejemplares" (Greimas 1971: 179). Sobre esa escena del mundo, convertida así en lenguaje (es decir, en significante), o mejor, en discurso (porque el universo significante es un universo en movimiento, sin lo cual no sería un espectáculo, sino a lo más un cuadro), "el contenido de las acciones cambia todo el tiempo, los actores varían, pero el enunciado-espectáculo sigue siendo el mismo" (Greimas 1971: 265).

A partir de ahí, se edificó todo lo que la semiótica estructural ofrece de más original, a saber, la proyección de toda una franja de problemáticas de la significación sobre una teoría de la na- 
rratividad. La invariante a la cual remite la visión estructurante que está aquí en cuestión -el elemento que seguirá siendo "el mismo" bajo la superficie de enunciados-espectáculos siempre diferentes-, no es otro, en efecto, que la sintaxis interactancial, cuyas unidades se encargarán de identificar la gramática narrativa -"un proceso, algunos actores, una situación más o menos circunstanciada" (Greimas 1971: 179)-, así como de explicitar las regularidades de su funcionamiento. A través de la observación de corpus textuales bastante variados, esa gramática será sistematizada durante los años setenta (Greimas y Courtés 1982). Ella constituye el núcleo de la teoría "greimasiana". Difundida con el nombre de "modelo estándar", sigue siendo la base de aplicaciones donde se reconoce, con frecuencia al pie de la letra, la enseñanza prodigada desde hace más de treinta años (Bertrand et al. 2007).

Reverso posible: aquello que había sido radicalmente innovador, quedó poco a poco fijado, tanto más porque la eficacia del modelo, en el plano operativo, parecía el ejercicio rutinario de un "hacer descriptivo" estrictamente programado que no dejaba lugar a ninguna interrogación sobre los fundamentos de la teoría, sobre sus presupuestos ideológicos o sobre sus implicancias antropológicas. $Y$ la idea de narratividad, en sí misma llena de promesas, se encerraría muy pronto en los límites de un esquema narrativo, pomposamente calificado de "canónico", como si hiciera falta, para fines pedagógicos, proclamar insuperable la sintaxis actancial particular que pone en marcha, a pesar de lo que su mismo autor veía en ella de contingente, de parcial y de provisional, y no precisamente para cerrar la reflexión, sino más bien para abrirla y para estimularla (Greimas y Courtés 1982, entrada: <<Narrativo (esquema-) >>, 8). Sin embargo, el trabajo de investigación propiamente dicho no se detuvo allí; en todo caso, no para todo el mundo, y menos ciertamente para Greimas mismo, quien llegó a decir en privado que había que "rehacer" la semiótica (Geninasca 1997: 42).

Para creer por fin en la posibilidad de relanzar la idea de recuperar un poco del tono intelectual de los comienzos y para convencernos, al mismo tiempo, de que era posible enlazar nuestros esfuerzos con la dimensión "existencial" de los inicios, nos ha bastado con releer a Greimas y con echar una mirada crítica a nuestra propia práctica. Lo que hemos descubierto es que si la mayor parte de las objeciones levantadas desde el exterior contra los trabajos de los "greimasianos" son justas, no son insuperables. Y lo que es más importante, que son superables desde el interior de la teoría misma (Geninasca 1997, Bucher 1997, Landowski 1997a, Kersyté 2009). Esa es la razón por la cual nosotros nos venimos ocupando desde hace algunos años en superar los bloqueos que han contribuido a sofocar las potencialidades de la disciplina, a impedir su 
desarrollo como proceder reflexivo y analítico anclado en la vida.

\section{Lo que hacemos con los textos y lo que los textos hacen con nosotros}

El primer obstáculo por superar era la confusión que se produce a propósito del objeto mismo de la semiótica. Greimas se vio envuelto de alguna manera en esa confusión, ya que, desde el fondo de América del Sur, al hilo de una conferencia, lanzó un buen día la fórmula que se convirtió en fuente de un lamentable malentendido, que revelaría ser persistente: "Hors $d u$ texte, point de salut!" [jFuera del texto, no hay salvación!]. Como se dirigía a un público de especialistas de la literatura, se trataba para él, trivialmente, de invitar a sus oyentes a ser coherentes consigo mismos, a trabajar sobre la literatura -en lugar de especular, como era entonces usual, sobre los parámetros de orden social, afectivo $\mathrm{u}$ otros que hubieran podido intervenir en el estadio de la génesis de las obras-.

Pero no fue eso lo que se entendió. La fórmula fue interpretada como un ucase, con el que se trazaba una frontera entre dos zonas: de una parte, los textos -los discursos verbales, de preferencia escritos- y de otra parte, todo lo que los rodea, zona decretada como prohibida, el "contexto", es decir, nada menos que la sociedad, la historia, lo real, la vida, e incluso cualquier otro texto distinto de aquel que se ha tomado como objeto específico del análisis, a pesar de los lazos intertextuales que condicionan la comprensión de todo discurso. Se confundía sencillamente objeto empírico y objeto de conocimiento. Porque si los textos son los objetos empíricos que interesan indudablemente a los semióticos, el objeto de conocimiento no es precisamente el texto: es el sentido. Ahora bien, el sentido, a diferencia del tesoro escondido en la cueva de Alí Babá, no es algo que uno pueda encontrar completamente constituido, colocado en el interior del "texto clausurado", esperando que alguien venga un día a tomar posesión de él.

Desde el momento en que uno admite que, al contrario, ningún objeto -texto u otro- contiene de esa manera su significación, sino que todo puede recibir una a condición de que un sujeto la construya. Tenemos que admitir también que el sentido que sería atribuido, en particular a un texto, depende constitutivamente, a la vez, del intertexto que tome en cuenta el que efectúa dicha construcción, y del "contexto" en cuyo interior se efectúa. O mejor, para emplear una terminología más adecuada, un discurso enunciado (verbal o no-verbal) adquiere sentido en función de la manera como los participantes de la comunicación construyan el sentido de la situación en la que se produce el acto de enunciación que los pone en relación. Los componentes de una situación semejante son semióticamente analizables (Landowski 1993, 2007a). Se trata, entre otras cosas, de la imagen que cada uno de los interlocutores se hace de su partenaire, 
combinación variable de competencias modales y de roles temáticos que definen el estatuto actancial y actorial de cada uno de los participantes en cuanto sujetos interactuantes. Una de las estrategias, comunes a la mayor variedad de discursos, consiste, como se sabe, en instalar en el enunciado simulacros para figurar a los participantes en la relación enunciativa a fin de orientar la actividad interpretativa del receptor conduciéndolo hacia una posición determinada de lectura, aquella, por ejemplo, de un objetor o de un confidente, o incluso, como ocurre con frecuencia en la publicidad, la de un mirón (Greimas y Landowski 1979, Landowski 2007a, 2007b).

La tarea de un semiótico no puede limitarse a estatuir lo que los textos podrían significar en razón de sus estructuras "inmanentes" únicamente. En la perspectiva de una investigación motivada por un mínimo de interés en los desafíos existenciales o, más modestamente, psicológicos, sociales, políticos, de las prácticas cotidianas del sentido, más pertinente que la insistencia en hipostasiar el texto en cuanto forma pura nos parece el objetivo que consiste en buscar cómo dar cuenta de lo que los objetos de sentido, leídos en situación, hacen de nosotros que los leemos. Dicho de otro modo, a partir del momento en que se considera que lo que importa es lo que pasa en la vivencia de la lectura concebida como operación que da sentido a objetos cualesquiera, son las condiciones de esa lectura las que se imponen como el principal objeto semiótico por describir (Landowski 2004).

Pero los elementos modales, actanciales y temáticos por medio de los cuales se construyen los simulacros discursivos de los participantes en la interlocución, así como su estatuto, su competencia y sus relaciones no son los únicos que entran en juego en la construcción de una situación en cuanto configuración significante. Intervienen también variables que, dependiendo más de lo sensible que de lo inteligible en sentido estricto, es decir, de lo cognitivo, movilizan nuestra aptitud casi innata para captar efectos de sentido que surgen de dispositivos de orden plástico o rítmico más que nuestra competencia, mal que bien adquirida, para reconocer las significaciones convencionalmente investidas en las unidades figurativas. En una palabra, más acá de lo cognitivo, el sentido -la inteligibilidad del mundoprocede también de lo estésico.

$\mathrm{Y}$ ahí encontramos otro punto de bloqueo.

\section{¿Narración o experiencia?}

Bajo el pretexto de que la dimensión sensible de los objetos de sentido no parece reductible a un juego de oposiciones categóricas, fácilmente denominables, y de que, además, no se ve claramente cómo podría articularse por medio de los esquematismos sintácticos que propone la gramática narrativa "canónica", los adeptos de 
la semiótica estándar juzgan más prudente ignorar dicha dimensión: por oposición a la positividad de las articulaciones sintáctico-semánticas que permiten dar cuenta de la acción y de las pasiones en el marco de análisis textuales en buena y debida forma, la experiencia sensible correspondería a lo inefable.

Existe en eso una extraña paradoja, porque nada sería más sustancial, más concreto, más encarnado (menos inefable) y al mismo tiempo menos difuso, más exactamente estructurado que los acomodos de las cualidades plásticas y rítmicas -en una palabra, estésicas- por medio de las cuales hacen sentido manifestaciones semióticamente tan diversas como unos compases de música o un movimiento de masas (visto o acompañado en la calle o visto en la televisión), como las expresiones cambiantes de un rostro o simplemente como la manera que cada uno tiene de estar frente a otro a lo largo de una conversación. Lo que en esos casos se deja ver, entender, sentir, no tiene ciertamente una significación del género de aquella que atribuimos a una palabra, a un texto. No por eso deja de ser una forma de comunicación, cara a cara o cuerpo a cuerpo, y que nos afecta. El hecho de que se instaure más acá de las palabras no implica que sus efectos de sentido no ofrezcan ninguna regularidad, y por consiguiente nada autoriza a postular que sus principios de funcionamiento escapan a toda forma de conocimiento distinta de la intuitiva.
En todo caso, lo que interviene a ese nivel influye tan fuertemente en el sentido que atribuimos a nuestra presencia mutua -el primer elemento del "sentido de la vida"-, que no vemos cómo podríamos, en cuanto semióticos, resignarnos a no tomarlo en cuenta.

El hecho de que haya ahí, además, una dimensión esencial de la experiencia estética es algo evidente. Pero al margen de la relación con las obras de arte, esa dimensión interviene prácticamente en todas partes, incluidos aquellos dominios que uno podría pensar que no están sometidos a las fluctuaciones de la sensibilidad. Especialmente en la política, dominio que tomaremos de ejemplo para justificar este punto.

\section{Entre historia y presencia}

Como los políticos hablan mucho, se ha cogido la costumbre, desde hace algún tiempo, de analizar sus discursos. Se ha tendido primero a poner de relieve los contenidos ideológicos, doctrinales, pragmáticos que en ellos se expresan, después nos hemos dedicado a describir los procedimientos de argumentación, de persuasión o de manipulación que actúan en ellos, y más recientemente, al constatar que ese género de discursos se dirige tanto a la afectividad como al intelecto, se ha tratado de dar cuenta también de los efectos emocionales o pasionales que consideramos que producen o promueven. Aunque lo "pasional" no es 
lo sensible, y la política no se detiene allí.

Hoy, por sus constantes apariciones en los medios, los políticos más visibles se nos han hecho tan familiares que la manera como los juzgamos no difiere apenas de la manera como tratamos a nuestros seres más próximos. Si estimamos a algunos de ellos, si otros nos exasperan, eso no depende únicamente de las posiciones que adopten ante tal o cual cuestión importante a nuestro modo de ver. Eso depende tanto o más de los efectos de sentido que se desprenden del porte, de la complexión, del ritmo de los movimientos y de las palabras, del tono de voz de cada una de esas personalidades, de su hexis ${ }^{3}$ propia, tal como se manifiesta a través del más mínimo gesto y que traduce una manera específica de estar en el mundo. Las formas de adhesión o de rechazo que inducen esos elementos dejan por definición poco espacio a los criterios de orden cognitivo. En el momento de una elección, pensamos evidentemente elegir entre los candidatos en función de aquello que "objetivamente" nos proponen. Pero la manera como los escuchamos, como comprendemos y juzgamos sus argumentos, y hasta nuestro grado de disponibilidad para reaccionar favorablemente a los estados pasionales de los que tratan de hacernos participar, todo eso depende de lo que experimentamos frente a su persona misma, tal como la "sentimos" de inmediato.

Sin duda, nada hay en eso de radicalmente nuevo y, sin embargo, en nuestros días, esa inflexión a favor de lo sensible afecta cada vez más el estatuto, las formas, el lugar mismo de lo "político" (Landowski 2008). Tiempo atrás, para el ciudadano medio, la política se situaba en un espacio algo abstracto, construido por los discursos de un número limitado de detentores de la palabra autorizada, periodistas y políticos en primer lugar, que se encargaban de dar un sentido a la historia, de explicar el presente y de trazar interpretaciones plausibles del porvenir, de tal modo que la vida colectiva parecía desenvolverse como una suerte de gran relato inteligible. Hoy en día, una manera totalmente diferente de vivir la política tiende a instalarse entre nosotros: hemos dejado de considerarla únicamente como un nivel de realidad objetivable en enunciados que adoptan la forma de pequeñas epopeyas o de grandes utopías que los oradores políticos han creído siempre que era su deber contarnos o proponernos. En lugar de eso, la vida política tiende a convertirse en un espacio de relaciones intersubjetivas vividas en el aquíahora a través de actos de enunciación que, por "medios" interpósitos, implican la co-presencia sensible de aque-

3 Hexis: Constitución, actitud, temple de ánimo [N. del T.]. 
llos que hablan y de aquellos que los miran y los escuchan. Esa relación es a la vez tenue -se vive al instante- $y$ profunda, porque procede de la relación, casi íntima, que cada cual contrae o cree contraer con esos hombres y con esas mujeres de carne y hueso, que para obtener nuestro voto se muestran a cual mejor ante nosotros. Por eso queremos políticos que no se escondan detrás de un supuesto saber; que no se mantengan a distancia, o lo que sería peor, que no se coloquen por encima de nosotros; en pocas palabras, que "no nos cuenten historias", o en todo caso, que no se limiten a eso. Lo que esperamos de ellos es que se arriesguen a una relación in praesencia, la cual se supone que nos permitirá sentir si nos "comprenden" o no.

La política que, según se dice, es el dominio del cálculo y de la razón fría, tiende así a convertirse en uno de los planos sobre los cuales aflora a la superficie la dimensión existencial de nuestra relación con el otro y se traduce en forma de gestos de adhesión o de rechazo a flor de piel. Hemos tenido en Francia una buena prueba de eso con ocasión de un debate crucial entre los dos candidatos de la segunda vuelta en la elección presidencial del 2007. Esa noche, muchos electores que dudaban en decidirse por uno de los campos -aquellos que los politólogos llaman "volátiles" o indecisos- se han decidido por uno o por otro candidato (mejor sería decir: por uno contra el otro) en función de la simpatía o de la antipatía que pudo inmediatamente hacer sentir el contraste entre las cualidades estésicas del modo de presencia de cada uno de ellos frente a su adversario, así como en la relación con los dos periodistas presentes en la escena, y, finalmente, frente a la cámara, es decir, frente a los electores.

Ese desplazamiento de lo político se puede condensar conceptualmente diciendo que si antes, para todo el mundo o casi, la política tenía significación, ahora, según las encuestas de opinión, para la mayor parte de la gente ya no la tiene, pero hace sentido según otro régimen semiótico totalmente diferente: así como vista en cuanto narración, ha perdido, cognitivamente, su credibilidad, vivida en cambio estésicamente como una de las formas de la experiencia, recupera su capacidad de movilización.

\section{La vivencia y su discurso}

Pero "la política" no es más que una construcción semiótica entre otras, y los dos regímenes de significación que acabamos de distinguir en su práctica -la experiencia, la narración - tienen un alcance mucho más general.

Las narraciones son las que nos permiten dar un poco de significación y de valor a la vida a pesar de lo que pueda tener de insignificante por su monotonía o de sinsentido por su aspecto imprevisible y caótico. Pero independientemente de las significaciones que conlleva lo que se cuenta, pasa 
a veces -frente a otro, o ante una obra, ante un paisaje- que nos sentimos cautivados por la presencia de un sentido que, si por hipótesis no emana de ningún discurso constituido, de ningún relato formal, se impone, no obstante, inmediatamente a nuestra intuición. Ese sentido segundo (o tal vez, en realidad, primero), la narración no lo cuenta, y no puede "contarlo". Para contarlo, tendría que reducirlo a su propio orden de significancia, que es el de las significaciones objetivadas, textualizadas, legibles -“de papel”, decía Greimas. Y, por naturaleza, ese género de significaciones solo puede reflejar muy imperfectamente las modulaciones del sentido vivido en la experiencia de nuestra relación con la gente y con las cosas mismas. Sin embargo, el hecho de que la experiencia así entendida -la del sentido- no sea contable, no implica que sea indecible. Toda una literatura se aplica, por el contrario, a decirla. De Proust a Sarraute, de Kafka a Musil, de Sterne a Woolf, de Leopardi a Svevo, de Dostoievski a Tsvetaieva, una pléyade de autores que ha proyectado sobre el mundo una mirada en cierto modo fenomenológica al pie de la letra, han sabido inventar formas de escritura constitutivas de eso que podríamos llamar el discurso de la experiencia (Landowski 2007c). Ese discurso es, ciertamente, distinto de la vivencia de la experiencia, pero tiene el poder de captar su movimiento y de restituir discursivamente la dinámica de la relación con las cosas, con el otro, consigo mismo, en la cual se funda la experiencia del sentido en su emergencia en acto. A tal punto que, ante ese tipo de textos, los lectores tenemos la impresión de participar de manera importante en el nacimiento del sentido. Y lo que es más, entre ese modo de tratamiento de la experiencia del sentido por la escritura "literaria" y su tratamiento por vías "científicas", la frontera es apenas discernible. Entre el proceder de Proust y el de MerleauPonty, ¿por dónde pasa la frontera, exactamente? ¿Y entre el Sartre de $L a$ náusea y el de la parte final de El ser y la nada, consagrada al análisis de la experiencia inmediata de lo "viscoso", de lo "resbaladizo", etcétera, análisis que desemboca en el proyecto de un "psicoanálisis existencial"?

Para construir ahora una semiótica existencial que llegase por sus propios caminos a tratar de ese sentido vivido, ni la gramática narrativa estándar ni sus prolongaciones relativas a las pasiones y a la tensividad ofrecen los instrumentos necesarios (Greimas y Fontanille 1991, Fontanille y Zilberberg 1998). La semiótica de las pasiones no hace más que extender a la sintaxis de los estados (de alma) la gramática modal anteriormente aplicada al "hacer" de los actantes de la narración; la semiótica tensiva, por su parte, proporciona un formalismo útil para analizar las variaciones de intensidad de cualquier fenómeno, pero no nos dice nada acerca de los determinantes cualitativos de los efectos de sentido captados por los sujetos (Landowski 2004: 44-49, 2005: 94-96 [2009b: 105-108]). El 
hecho de que, en esas condiciones, nos encontrásemos relativamente desprovistos de instrumentos para dar cuenta de la experiencia, ¿es razón suficiente para ignorar todo aquello que escapa a las rejillas de análisis construidas para describir la narración? Por nuestra parte, lejos de sacar de la limitación de nuestras conquistas teóricas y metodológicas la conclusión de que la cuestión existencial no es pertinente o de que el estatuto del sentido aprehendido en la experiencia no puede ser sino extrasemiótico, creemos que el problema radica en lo incompleto de los modelos de que disponemos. $\mathrm{Y}$ en ese sentido, hemos tratado y seguimos tratando de completarlos y de hacerlos cada vez más potentes.

\section{La óptica sociosemiótica}

Pasar de una semiótica del texto a una semiótica de las situaciones, y luego, de la experiencia, exigía ampliar el campo de pertinencia con relación a la práctica dominante. En eso consiste principalmente la especificidad de la versión de la semiótica general que nosotros hemos elaborado con el nombre de sociosemiótica. Esa extensión corresponde al mismo tiempo a una profundización, en el sentido en que conduce de lo que es más exterior al sujeto -el texto, en su objetividad de "enunciado enunciado"- a lo que es más propio, más "interior" del sujeto -la experiencia del sentido tal como él la vive-, pasando por un nivel inter- medio, la situación como configuración significante construida intersubjetivamente por los coparticipantes en la interacción.

Para efectuar ese recorrido, ha sido necesario crear un cuerpo de conceptos nuevos, tales como los de unión, contagio, ajuste, asentimiento, realización (culminación)... Conceptos que han sido ya objeto de definiciones, las cuales no vamos a reproducir aquí en detalle (Landowski 2004, 2005). Nuestro objetivo se sitúa en un plano más global: quisiéramos mostrar cómo la teoría ampliada a la que hemos llegado nos acerca a la vida, sin renunciar por eso al rigor que exige la "ciencia". Esta gran palabra no sirve más que para adornar un proceder más modesto que se podría resumir así: reordenamiento de los dos componentes de base -narrativo y figurativo- en los que se funda la teoría semiótica clásica del discurso, y renovación de la manera de articularlos entre sí. Vamos a precisar ese compromiso a continuación.

\section{Lógicas complementarias de la junción y de la unión}

En la base de la gramática narrativa llamada estándar, se encuentra la hipótesis implícita de que todas las fluctuaciones que afectan nuestra condición material y moral de sujetos dependen de operaciones de "junción" que, unas veces, nos ponen en posesión de los "objetos de valor" a los que apuntamos (=conjunción); otras veces, 
nos privan de ellos (=disjunción). Un modelo semejante se justifica respecto de un espacio de interacción concebido como espacio cerrado y saturado -típicamente, el del cuento- en cuyo interior lo que un personaje pierde, otro debe recibirlo como participación. Y tiene la ventaja de prestarse a cierta formalización. Pero tiene el inconveniente de ser ideológicamente demasiado marcado. Una gramática de la intersubjetividad concebida como enteramente mediatizada por la circulación de los objetos, que desemboca en recorridos de vida cuyo sentido se reduce a relaciones de posesión, traduce una visión extremadamente estrecha, puramente económica, de las relaciones humanas. Desde el tener más concreto hasta el saber más abstracto, todo se mide ahí en valores tesaurizables o consumibles, por un lado, o en valores modales, por otro, todos los cuales tienen vocación de transitar entre poseedores a la manera de mercancías, a la espera siempre de cualquier nuevo adquiriente (Landowski 2004: 73-76).

El redescubrimiento de los años noventa, unido a la aparición del último libro de Greimas, De l'imperfection (Greimas 1990), al mismo tiempo que a la relectura de los fenomenólogos franceses de la posguerra, consistió en darnos cuenta de que existen también, en cuanto positividades semióticamente analizables, interacciones independientes de toda transferencia de objetos entre sujetos. Para retomar una expresión de Sartre, independientemente de las relaciones de posesión que establecen entre sí sobre lo que consideran que pertenece al orden del tener, los sujetos viven también entre sí y con relación a lo que los rodea, algunos "lazos de ser" (Sartre 1984: 325). O, con una terminología tomada de Merleau-Ponty, antes de descomponerse en unidades discretas para ofrecerse a nuestra captación y a nuestra codicia, el mundo se nos presenta como totalidad que hace sentido: nuestro estar en el mundo, en cuanto tal, inmediatamente (sin pasar por la mediación de objetos socialmente categorizados y valorados) hace que haya, o que pueda haber sentido en nuestras relaciones con el otro $y$, en general, con lo real que nos rodea (Merleau-Ponty 1975).

En términos semióticos, eso quiere decir que al lado de un régimen de significación articulado en torno a la idea de junción, debemos dar cabida a otro régimen de sentido, fundado en la copresencia sensible de los actantes entre sí. En ese marco, los objetos no son reducibles a magnitudes intercambiables, cuyo valor se aprecia con criterios de orden funcional, fijados por referencia a programas de acción predefinidos. Aprehendidos en cuanto realidades materiales, hacen sentido gracias a cualidades sensibles que pueden descubrir en ellos sujetos dotados de algo esencial que no aparecía en el régimen narrativo precedente: de un cuerpo. Aquellos que a lo sumo eran inteligentes, capaces de conocer, de juzgar, de decidir, de evaluar a distancia y desde fuera, son ahora, 
además, sensibles, sensorialmente receptivos ante las cualidades estésicas de los seres con los que entran en relación. Y desde ese momento -desde que un actante es capaz de sentir estésicamente al otro, que está frente a él, de captar su manera propia de estar en el mundo- queda abierta la vía para una forma de relaciones que no dependen de la junción, sino de eso que nosotros denominamos la lógica de la unión. Esta relación no anula las identidades. Al contrario, tiende a exaltarlas al ponerlas en contacto y al hacerlas interactuar en función de su sensibilidad recíproca. La unión no es la fusión; tampoco es un estado. Es un modo de interacción (y al mismo tiempo, un modo de construcción de sentido), en cuyo marco, las partes llegan -en el mejor de los casos- a constituir, conjuntamente, dinámicamente y por ajuste mutuo, una entidad compleja nueva, una totalidad inédita, en la cual cada una de las partes que la integran encuentra la forma de su propia realización (Landowski 2004, 2009b).

La complementariedad entre esas dos lógicas, la de la junción y la de la unión, permite integrar el conjunto de los componentes de la competencia semiótica -no solamente modal, sino también estésica- de los sujetos analizados. Y lo que es más, esa dualidad de regímenes tiene vocación de aplicarse igualmente a los metasujetos que somos nosotros en cuanto semióticos y analistas. Lo mismo sucede con la posibilidad de una semiótica existencial. Una semiótica seme- jante no puede construirse más que en una relación dialéctica con lo que ella analiza: a la vez en unión (según un régimen de relación sensible) y en posición de exterioridad objetivante (según el vocabulario juntivo $\mathrm{u}$, hoy en día, tensivo), salvo que en la práctica, las tareas correspondientes se hallen provisionalmente repartidas entre actores-investigadores distintos. Por nuestra parte, en todo caso, asumimos la intención de conocer de otro modo, "uniéndonos", en la medida de lo posible, al otro. Cualesquiera que puedan ser la forma y el estatuto de ese "otro" -interlocutor, texto, obra o elemento del mundo natural-, se trata siempre de comprenderlo acercándonos a él como a un sujeto, que consideramos también sensible, sabiendo que otros investigadores, preocupados por modelizar su funcionamiento en cuanto objeto, sabrán distanciarse metodológicamente cuanto sea necesario.

\section{Regímenes de sentido en la interacción}

Una vez sobrepasados los límites del modelo juntivo, nuevas posibilidades se abren para una teoría general de la construcción y de la aprehensión del sentido en la interacción. Comencemos a este propósito por algunas generalidades.

Cualquiera que sea el proyecto por realizar, el proceder que hay que poner en marcha, el problema que tenemos que resolver o el asunto que gestionar para llegar a buen término, es un hecho empíricamente constatable: que 
cada cual, en la vida cotidiana, está inclinado (en función de su cultura o de su idiosincrasia personal) a privilegiar un modus operandi determinado, un cierto estilo de acción, una "estrategia", de preferencia a tal o cual otra. Muchos, no sintiéndose en confianza más que en un entorno ordenado y controlado, soñarán con poder programar el comportamiento de la gente al igual que el curso de las cosas, a fin de asegurar hasta en el más mínimo detalle, el control del desarrollo de la operación en la que se hallan implicados. Otros habrá que, no viendo en todas partes más que maquinaciones y complots, creen que no podrán llegar a su fin si no es manipulando, de manera tan forzada como fuere necesario, a aquellos que tienen que tratar. Algunos preferirán fiarse de su intuición, de su olfato, de su capacidad de sentir en el momento los resultados de una situación o las disposiciones de aquellos con los que algo tienen que ver, listos para ajustarse a ellas y sacar el mejor partido posible, tomando la ocasión "por los cabellos". Otros, finalmente, descartando toda idea de plan, de cálculo o de sintonía con el otro, creerán que es más seguro dejarse llevar por su buena estrella y se contentarán con cruzar los dedos esperando algún feliz accidente que la providencia haya decidido preparar para ellos.

Esas distintas maneras de ser, que corresponden a diferentes modos de concebir el sentido de la vida, se traducen en estilos de conducta diferenciados por el tipo de interacciones que entablan con los objetos, con el otro y consigo mismos. Dichas variantes dependerían únicamente de datos psicológicos y no tendríamos nada más que hacer sino constatar si los regímenes de sentido y de interacción a los que remiten se articulan unos con otros en función de principios estructurales que nada deben a la psicología y que por el contrario, revelan ser semióticamente analizables. Sin embargo, entre esas configuraciones que, intuitivamente, nos son tan familiares, la semiótica narrativa no había reconocido ni tematizado hasta el presente más que dos: la "operación" o acción programada sobre las cosas, y sobre todo, la "manipulación" entre sujetos. Retomando las definiciones clásicas de esos dos regímenes, no será difícil poner de manifiesto las bases sobre las cuales reposan, respectivamente. El primero se funda en un principio general de regularidad, caracterizado por la inmutabilidad de los "roles temáticos" asignados a los protagonistas de la acción. Este principio garantiza (en principio) la eficacia de nuestras intervenciones sobre el mundo que nos rodea. El segundo procede de un principio de intencionalidad, cuya aplicación supone el reconocimiento recíproco de los participantes en la interacción en cuanto actantes sujetos dotados de "competencias modales" (del tipo creer, querer, saber, poder), que cambian sin cesar. De ese modo, la gramática narrativa ha colocado en un sitial de honor la figura del manipulador y, más accesoriamente, la del programador. 
En cambio, ni el sujeto que confía en su capacidad de sentir in vivo las potencialidades de una situación, de convertir en ventaja la "propensión de las cosas" (Jullien 1996) o de la gente, a captar y a explotar el kairós ${ }^{4}$-bauticémoslo, a falta de mejor término, el oportunista-, ni el fatalista decidido a someterse al azar, no encontraron lugar en ese marco. La observación de la interacción, y sobre todo de la experiencia que de ella tenemos, obligarían, no obstante, a tomarlas también en consideración. Para analizar, por poco exhaustivamente que fuera, las prácticas efectivas, era necesario, por consiguiente, abrir el abanico de las formas de narratividad. De ahí la introducción, al lado de los dos regímenes "estándar" mencionados hace un instante (que, si pierden su monopolio, no pierden nada de su pertinencia), de dos regímenes complementarios fundados, respectivamente, en un principio de sensibilidad y en un principio de suerte [aléa]: el régimen del "ajuste" (al otro) y el régimen del "asentimiento" (a los decretos de la suerte, a los "accidentes" de la vida) (Landowski 2009b: 70-81). Tenemos así:

\section{Regímenes de interacción}

\author{
Régimen de \\ interacción fundado \\ en la regularidad: \\ la programación \\ (Estrategias del \\ "programador"). \\ Régimen de \\ interacción fundado en la \\ intencionalidad: \\ la manipulación \\ (Estrategias del \\ "manipulador").
}

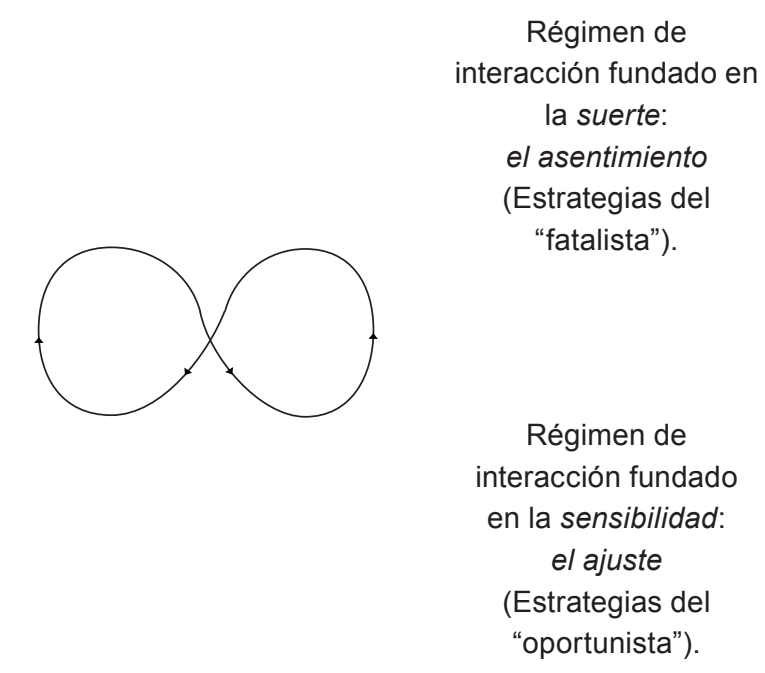

4 Kairós: ocasión, oportunidad [N. del T.]. 
Formando sistema y con vocación de combinarse entre sí, las cuatro fórmulas a las que hemos llegado permiten dar cuenta de la variedad y del carácter, casi siempre heterogéneo, de las prácticas interaccionales observables en los terrenos más diversos, incluida la construcción del objeto de conocimiento de nuestras disciplinas con pretensión científica (Landowski 2006). Sin embargo, para reformular la cuestión del "sentido de la vida" y para que estas reflexiones desemboquen en la producción de instrumentos de análisis, no basta con repensar de esta manera las formas del "pequeño espectáculo" que interpretamos para constituir el universo medioambiental que nos rodea en un mundo significante, para extraer de él los principios implícitos que contiene y para ampliar las fronteras de la narratividad. Habría que reexaminar también el estatuto, las formas y el rol de la figuratividad y más aún la manera de concebir su articulación con el componente narrativo.

\section{Formas de estar en el mundo}

Según las circunstancias, en función de los contextos, del tipo de objetos que se presenten y de la naturaleza de las relaciones que tratemos de establecer con lo que nos rodea, oscilamos, en la vida misma, entre dos maneras muy diferentes de mirar el mundo y de hacerlo significar. En el marco de una problemática semiótica de alcance general, una y otra deben ser tomadas en consideración.

\section{La lectura y la captación}

Con mucha frecuencia, miramos el mundo como si se tratase de una superficie cubierta de signos que hemos aprendido a leer. La comprensión de aquello con lo que nos enfrentamos pasa entonces por el desciframiento de formas manifiestas que, verbales o no verbales, constituyen el equivalente de otros tantos textos que suponemos que "quieren decir algo" o, según la fórmula adoptada más arriba, que "tienen significación". Pero podemos no mirar el mundo como una red de signos que hay que descifrar. Ante nosotros, no hay nada que descifrar, nada que leer, ningún texto. Y paradójicamente, hay ahí ya, de todos modos, sentido y valor. $Y$ es que, a falta de buscar por todas partes, un poco obsesivamente, las marcas de discursos inteligibles que nos serían dirigidas (intencionalmente o no), nos atrevemos algunas veces a sentir el placer, y al mismo tiempo tal vez el riesgo, de apartar nuestras prevenciones y de dejarnos impregnar sin reservas por las cualidades sensibles inherentes a los seres y a las cosas mismas, cuya presencia nos rodea. El régimen de la lectura del mundo queda ahora desplazado por el régimen de la captación de un mundo vivido en cuanto que "hace sentido". 
Es cierto que con frecuencia podemos tener el sentimiento de que existe una concordancia entre esas dos modalidades de la mirada o, más generalmente, entre esos regímenes de significancia. Así, en una conversación, mientras que el tono de nuestro interlocutor parece corresponder al contenido de lo que nos está diciendo, nosotros no tenemos ninguna razón para disociar la captación de la lectura -lo estésico de lo cognitivo-, puesto que precisamente los efectos de sentido que sus inflexiones de voz nos permiten captar a través del modo impresivo se encuentran validados por su conformidad con lo que nos parece ser la significación articulada e intencional de sus palabras. La distinción no deja de ser pertinente en principio, y útil en la práctica desde el momento en que deja de haber concordancia. Pero, sobre todo, vale más en otro plano, de orden metasemiótico, donde se plantea la cuestión de las implicaciones "existenciales" que abre la alternativa entre esos dos regímenes.

Por un lado, para hacerse uno lector y para mirar el mundo a la manera de un texto, es preciso que el sujeto se separe de lo que ve, lo objetive, lo observe como una realidad en sí misma significante, interpretable, potencialmente inteligible, incluso si no devela de entrada su significación. Visto desde esa perspectiva, un texto, o todo objeto considerado como tal, es un objeto autónomo, mantenido a distancia, que sirve de soporte a significaciones supuestamente ya constituidas, y que tenemos que descubrir. Por enigmático que pueda parecer a primera vista, tal texto se presume descifrable por definición. Basta con encontrar la clave. Toda lectura, en esas condiciones, equivale a una decodificación, $\mathrm{y}$, en ese sentido, depende esencialmente de una hermenéutica, o incluso de una semiología, cuando las reglas de codificación están suficientemente estabilizadas y formalizadas (por ejemplo, gracias a algún sistema semisimbólico») (Floch 1986: 26-27 y ss.).

Por oposición, un proceso indefinidamente abierto (y propiamente semiótico) preside la emergencia del sentido en la experiencia que constituye la captación. Ese efecto de apertura reside en que, aquí, el sujeto se implica directamente en su relación con el objeto: en el mismo momento en que esa relación se establece y lo pone a prueba por la manera como se articula con él, el sujeto vive su propia presencia ante el objeto en cuanto que hace sentido. De eso resulta que, a diferencia de la "significación", que no aparece más que al término de un trabajo de desciframiento, el "sentido" constituye más bien un punto de partida: captado en el instante, es él y no el texto el que crea enigma para el sujeto. Es él el que el sujeto tiene que esforzarse en comprender, a no ser que, dado el caso, opte por recategorizarlo en los términos de algún esquema de significación -de alguna narración- más o menos convencional. A ese sentido 
que el sujeto acaba de captar ¿qué sentido -o qué significación- se le puede atribuir? El enigma del texto-objeto, o sea, la cuestión de su significación era, por naturaleza y en principio, resuelto por la lectura; en cambio, la cuestión del sentido - del "sentido vivido" en la experiencia- no tiene solución de ese género, puesto que el sentido que nace entonces es el que surge de la relación misma que se establece hic et nunc entre el sujeto y su objeto: por esa razón, el enigma que plantea al que de él hace la experiencia no tiene fin. ${ }^{5}$

Al oponer la lectura de las significaciones (que dependen de la narración) a la captación de las cualidades sensibles (que hacen sentido en la experiencia), no queremos sugerir que el primero de esos regímenes no concerniría más que a nuestras relaciones con los textos (en cuanto objetos legibles por naturaleza), o más generalmente, a lo verbal (concebido como lo inteligible por excelencia), por oposición al segundo, que tendría el rasgo específico de lo no-verbal (asimilado de frente a lo sensible). Cada uno de esos regímenes se define por la naturaleza de la mirada que echa sobre el mundo y no por una clase particular de objetos a los cuales se aplicaría exclusivamente. Lo cual quiere decir que para un sujeto que se coloca bajo el régimen de la lectura, cualquier objeto puede tener lugar de texto, dicho de otro modo, puede ser mirado como portador de significaciones; y que, inversamente, para aquel que se coloca bajo el régimen de la captación, todo objeto, incluso un texto, puede ser mirado como algo que hace sentido más allá de aquello que significa en términos lingüísticos o narrativos. Pero entonces, ¿cómo significa? Simplemente (si se puede decir) a través del modo estésico, $\mathrm{O}$, si este término corre el riesgo de crear problema, por medio del modo "figurativo".

\section{Formas de la figuratividad}

En la arquitectura de la teoría semiótica, la "figuratividad" se define, como se sabe, en relación con la "narratividad": esos son dos conceptos genéricos que remiten, el primero -la figuratividad-al componente semántico del discurso, el segundo -la narratividadal componente sintáctico. En cambio, cuando el término "figuratividad" se utiliza como instrumento de análisis de un discurso particular, la noción de figuratividad adquiere un carácter más técnico. La palabra designa entonces un conjunto de formas discursivas con valor icónico que representan los objetos del mundo, o con valor indicial, encargadas de señalar inferencialmente su presencia: esa es

5 A título de ejemplo de esas dos posturas, analizadas, respectivamente, a partir de un texto de Lévi-Strauss y de una página de Proust (Landowski 2004: 294-303). 
la figuratividad stricto sensu, también reconocida como figuratividad de superficie ( $b$ en el cuadro siguiente). Pero a eso se añade una tercera acepción del término, porque al lado de la figuratividad de superficie, hemos tenido que reconocer una figuratividad profunda ( $c$ en el cuadro siguiente), cuyos efectos de sentido dependen de la estesis y se basan en la organización rítmica y plástica (por ejemplo, cromática) de los elementos que componen la manifestación discursiva:

Durante largo tiempo, tanto en semiótica visual como en semiótica lite- raria, el tratamiento de lo "figurativo" se ha reducido a la consideración de la fórmula de tipo $(b)$ : uno se limitaba a reconocer en la superficie de los discursos figuras actoriales, espaciales o temporales más o menos codificadas por el uso, que se consideraban como las encargadas de proporcionar el "ropaje discursivo" a los dispositivos más abstractos organizados por la sintaxis narrativa. A ese principio obedece todo buen lector: atento al más mínimo índice susceptible de "querer decir" algo, enlaza unos con otros los elementos de la manifestación discursiva

\section{EL DISCURSO \\ COMO TOTALIDAD}

Narratividad
Figuratividad

(en sentido genérico)

(a)

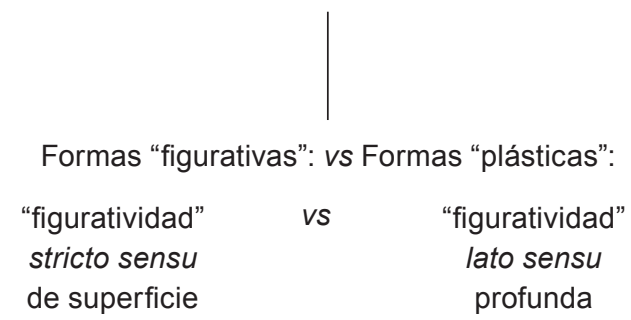

(b) 
-decorados, vestidos, fisonomías, gestos, etcétera- $\mathrm{y}$, a partir de ellos, trata de reconstruir la estructura actancial y modal subyacente a las acciones y a las pasiones, de donde el espectáculo del mundo, visto como narración, sacará finalmente su significación.

$\mathrm{Al}$ contrario, considerada según la fórmula (c), la figura impone la presencia del sentido tal como emana de las articulaciones plásticas inmanentes al objeto sensorialmente percibido. Greimas habla a este propósito de una "lengua otra", de un "lenguaje segundo", con cuya ayuda no solamente las obras -pictóricas, poéticas u otrassino también los objetos del mundo natural nos "hablan de otra manera": de manera distinta a como lo hacen a través del filtro de las lenguas naturales y de las rejillas culturales que hemos aprendido a aplicarles para leerlos reconociendo en ellos "objetos nombrables" (Greimas 1984: 12). Se podría preguntar, sin embargo, si más que "segundo", ese lenguaje plástico, o en general, estésico, que no designa nada y sin embargo nos habla por medio del juego de las cualidades sensibles que pone a trabajar, no es en realidad «primero». Eso es lo que Greimas sugiere cuando observa que "la narración no aparece, en toda su figuratividad desbordante, más que como el 'ruido' que hay que superar para po- der descubrir las principales articulaciones del objeto" (Greimas 1984: 24). Ese ruido de la narración es el que produce la figuratividad de superficie a la cual se atiene la lectura. Por oposición, las articulaciones principales -principales no en absoluto, sino porque dan acceso a lo que se puede considerar como el sentido "profundo" del objeto, como su sentido "mítico" o incluso existencial- son las articulaciones que organizan las formas plásticas constitutivas de la figuratividad profunda de la cual tenemos experiencia a través de los procesos de la captación. ${ }^{6}$

Dicho esto, nos queda aún por dar un último paso. No basta con tratar un poco formalmente de la figuratividad, en un capítulo aparte aunque eso sea bastante usual. Si se quiere medir todo el alcance del rol que cumple en la emergencia del sentido, es preciso ponerla en relación con las formas que recubre el modelo presentado más arriba en lo concerniente a la narratividad, dado que allí se dan dos componentes indisociables de todo discurso. Por lo que respecta al componente figurativo, acabamos de distinguir dos grandes regímenes de significancia: la lectura y la captación. La primera, definida como desciframiento de las significaciones vinculadas a lo figurativo stricto sensu; la segunda, como procedimiento que hace surgir el sentido

6 Sobre la idea de una jerarquía entre regímenes de sentido y sobre el privilegio que se puede otorgar a la captación con relación a la lectura, confróntese Cl. Lévi-Strauss (1955: 121) y nuestro comentario en Passions sans nom (Landowski 2004: 180-182). 
a partir de la figuratividad profunda (dicho de otro modo, a partir de lo estésico). Por lo demás, hemos construido un modelo narrativo ampliado, en el que se interdefinen cuatro regímenes de interacción (la programación, la manipulación, el ajuste, el asentimiento). Se trata ahora de considerar las relaciones entre esas dos configuraciones. Nuestro postulado consiste en afirmar que se establecen correlaciones sistemáticas entre regímenes de significancia y regímenes de interacción.

\section{Estilos existenciales}

La primera de esas correlaciones consiste en que el desciframiento de las significaciones a través de la lectura del mundo -de sus figuras de superficie- corre paralelo, en el plano de la interacción, con comportamientos que pertenecen a uno $\mathrm{u}$ otro de los dos principios en los que la teoría semiótica estándar basa el resorte gramatical de toda narración: ya sea el principio de intencionalidad que funda la sintaxis de la manipulación, ya sea el principio de regularidad que presupone toda programación, o, por último, una combinación de los dos.

Esa correlación no la establecemos inspirados por cualquier visión a prio$r i$; ni es tampoco fruto del azar. Encuentra su razón de ser en el hecho de que el proceso de la lectura es por sí mismo del orden de la programación: ¿toda lectura, en efecto, no tiene por condición de posibilidad la regularidad del código que pone en marcha para reconocer las significaciones del texto o, más ampliamente, del mundo visto como superficie textual? Y leer, ¿no es acaso, por naturaleza, entrar en el juego de la persuasión y de la interpretación, dicho de otra manera, en el juego de la manipulación? En los términos del Diccionario de Greimas/ Courtés, eso quiere decir que toda lectura tiene, en el fondo por "programa de uso", una programación y por "programa de base" una manipulación (Greimas y Courtés 1982, entrada: <<Programa narrativo $>>, 4,5,6$, 7.). La afinidad que ponemos de relieve entre esos dos regímenes, entre una manera determinada de interpretar el mundo y una manera correspondiente de actuar en él, es, pues, de orden propiamente estructural. Y podríamos mostrar que una relación del mismo orden asocia la captación al otro par de regímenes de interacción, a saber, el ajuste y el asentimiento. Pero nos limitaremos a dos ilustraciones.

Un perfecto ejemplo de la primera correlación se encuentra en Stendhal, con el personaje de Julien Sorel. ${ }^{7}$ Leerprogramar-manipular, o mejor, leer a fin de poder programar o manipular, tal es la combinación de modos operativos que le vemos adoptar en toda

7 Personaje central de Rojo y negro [N. del T.]. 
circunstancia, ya sea para analizar sus relaciones con otros, para rectificar sus decisiones o, de manera general, para orientar sus comportamientos. En todos los dominios -mundano, amoroso, político- Julien es a la vez, en el plano de la significancia, un lector, y en el plano de la acción, un intrigante, programado para manipular. Y lo que es más, el programa de vida que lo guía está a su vez sacado de una lectura (el Memorial de Sainte-Hélène), de suerte que todo su recorrido existencial procede explícitamente de una narración primera que le sirve de norma: para él, la narración prefigura la vida y sustituye a la experiencia. Aventuramos esta pequeña impertinencia: en todo eso, en ese empeño por dominar el mundo aplicándole, cueste lo que cueste, los procedimientos mismos que formalizan los esquemas canónicos de la década de 1970 y los llamados "patémicos", derivados de ellos, ¿Julien Sorel no sería una encarnación anticipada del perfecto Semiótico Estándar? Sea lo que fuere, así como nosotros hemos admitido la posibilidad de un "discurso de la experiencia" distinto de la "vivencia de la experiencia", aunque con poder de elevarse a su altura y de tomarlo semióticamente a su cargo, vemos que hace falta admitir ahora, además, que el discurso de la narración tiene, también, un poder en relación con lo vivido: no el poder de exaltarlo recreándolo, sino a la inversa, el de enmarcarlo por adelantado en sus rejillas de clasificación, y con eso, de reducir- lo, si no de rebajarlo, al rango de una simple vivencia de la narración.

El caso diametralmente opuesto nos lo proporciona un personaje de Dostoievski, M. Goliadkin, en El doble. Incapaz de dominar los códigos del medio en el que se desenvuelve, no logra descifrar ninguna significación de las intrigas que se traman en torno de él: es un lenguaje que él no sabe "leer". En cambio, apenas entra en contacto con otro, proliferan a sus ojos, en el modo de la captación, una multitud de efectos de sentido dramáticamente enigmáticos, que proceden o bien del principio de sensibilidad o bien del principio de la suerte. Es decir, que en su relación con las formas de la figuratividad, M. Goliadkin es típicamente un no-lector; sensible hasta el exceso a las cualidades plásticas de las manifestaciones con las que tiene algo que ver, no percibe su entorno sino como un sueño, o más exactamente como una pesadilla. Y en la interacción, es decir, en términos de narratividad, es exactamente lo contrario de un manipulador programado: se comporta (a su manera, o sea, con extrema torpeza) como una suerte de danzarín, en el sentido en que todas su mociones no son jamás sino reacciones inmediatas a los impulsos sensibles que vienen del otro, al cual trata de ajustarse a cada instante ( $\sin$ lograrlo). A lo cual se añade el hecho de que, como verdadero fatalista, está de antemano íntimamente resignado a aceptar los golpes de la suerte que él 
mismo anticipa al mismo tiempo que niega, por así decirlo, mágicamente, su inminencia.

La simetría entre los dos personajes es casi perfecta. El héroe de Stendhal es tan refractario a los datos estésicos de la experiencia como el de Dostoievski es ciego a los signos convencionales de la narración. Si la impermeabilidad de Julien a los reclamos de lo sensible hace de él (como el narrador lo subraya en varios pasajes) un "tonto", la ceguera de Goliadkin frente a las significaciones más elementales del texto social hace de él un idiota, un ridículo, un marginal y muy pronto un psicópata destinado al asilo. Mientras que uno, como observador distante de su entorno, tanto más lúcido cuanto más desligado está de sí mismo, planifica fríamente sus acciones anticipando las reacciones del otro; el otro, como en una sucesión de alucinaciones, se encuentra bamboleado por una serie de accidentes estésicos imprevisibles, cuya irrupción le impide toda estrategia eficaz. Y finalmente, así como habrá que esperar hasta los últimos capítulos de la novela de Stendhal para que Julien vislumbre lo que hubiera podido ser la experiencia del sentido, de igual manera, es preciso que M. Goliadkin tenga su doble -un "M. Goliadkin número dos", manipulador astuto, que podríamos tomar casi por otro Julien Sorel- para que el régimen "canónico" de la narración encuentre también su lugar en la novela de Dostoievski.

Tales conexiones entre regímenes de sentido y regímenes de interacción implican que a cierto nivel de profundidad, tenemos que ver con dispositivos de carácter más general que los subsumen. Dichos dispositivos, determinando al mismo tiempo la manera preferencial como un sujeto es llevado a hacer significar las realidades que lo rodean, y la manera según la cual tiende a interactuar con esas mismas realidades, traducen la manera, propiamente existencial, de estar en el mundo a la cual tiende la identidad de los personajes en cuestión, y sin duda también -con todas las variantes, matices y complejidades imaginables- la de cada uno de nosotros. En términos muy generales, mientras que algunos viven la vida al modo de la experiencia, es decir, de la captación y del ajuste-asentimiento, otros parece que la conciben e incluso que la viven como una narración, en cuyo caso, el mundo se presenta a sus ojos como un universo a la vez legible, ya que está cubierto de figuras nominables e inteligibles, y controlable, es decir, poblado de copartícipes o de adversarios manipulables y de objetos destinados por naturaleza a conformarse a sus programas. ${ }^{8}$

8 Sobre la "filosofía" propia de cada una de esas "constelaciones" (término de G. Simmel), una, vista como esfera de la aventura, la otra, como esfera de la prudencia; confróntese Interacciones arriesgadas (Landowski 2009b: 88). 


\section{Conclusión}

Cada una de las configuraciones semióticas de las que nos hemos ocupado recubre, por consiguiente, a la vez, desde el punto de vista de la teoría general del sentido, algunos modos determinados de tratamiento de la figuratividad, y desde el punto de la teoría de la acción, algunas formas precisas de la narratividad, y el conjunto permite dar cuenta de la diferenciación de los tipos de actitudes y de prácticas que cada individuo (y, por extensión, cada cultura) tiende a privilegiar frente a la cuestión del sentido de la vida. Lo cual quiere decir que tratar de la experiencia no obliga de ningún modo -como tampoco lo hace descifrar la narración- a salir del campo conceptual en el que las nociones de figuratividad y de narratividad encuentran su pertinencia. Simplemente, así como la figuratividad de superficie, privilegiada por el discurso de la narración, difiere de la figuratividad profunda que vemos principalmente operando en el ámbito de la experiencia, del mismo modo los modelos de narratividad de tipo programático y manipulador que dominan la narración difieren entre sí, en forma de ajustes y de asentimientos, con los que articulan fundamentalmente la experiencia. Una vez reconocidas, explicitadas y conceptualizadas esas diferencias, el campo existencial en el que intervienen se abre a nuestros análisis.
Pero esas distinciones tienen también un alcance más general. Tomando en cuenta todo lo que precede, la "narración" es en el fondo el conjunto de los discursos que fijan la identidad, la regularidad, la necesidad y la racionalidad de todo lo que existe. Se trata de un discurso de la aserción: discurso de lo inteligible, el cual, ante la experiencia incierta de lo real, permite fijar significaciones reconocibles, legibles, porque se supone de antemano que se hallan instaladas en la forma manifiesta de lo que es. A la inversa, la experiencia es interrogación sobre el sentido de los efectos del sentido que surgen de lo que adviene al sujeto, sea desde fuera en forma de figuras estésicas que lo impresionan, lo conmueven, lo afectan, sea desde dentro de sí mismo en forma de impulsos que provienen de la dinámica del cuerpo propio y tal vez también -sobre todo si se opta por incluir el sueño en el campo de la experiencia-que-hace-sentido- de figuras fantasmadas que traducen las pulsiones del "inconsciente". El sujeto puede dejarse llevar por esas fluctuaciones, o al contrario, esforzarse por dominarlas, tratando de reducirlas a esquemas tomados del universo de la narración. Pero puede también tratar de decirlas por medio de la producción de un discurso de la experiencia, capaz de recuperar reflexivamente y de restituir para sí mismo y, dado el caso, para otros aquello que antes ha hecho sentido en la vivencia de la experiencia, es 
decir, en la captación inicial. Porque si, como hemos dicho, la experiencia no es narrable, no por eso es, en principio, menos decible, por medio de formas de expresión y de escritura adecuadas, literarias o cinematográficas, y también fenomenológicas, y hasta algún día, por qué no, semióticas.

Como hemos visto, no es necesario incurrir en el misticismo para hablar de la experiencia, sea como vivencia o como discurso y para tratar de ponerla en paralelo con el discurso y hasta con la vivencia de la narración. Textualizadas o no, tenemos ahí configuraciones tan positivas las unas como las otras. $Y$ en consecuencia, si la dimensión existencial de nuestra relación con el sentido nos presenta un desafío, podemos emprender su análisis sin abandonar la semiótica.

\section{Bibliografía}

Bertrand, Denis; Dézé, Alexander y Jean-Louis Missika (2007). Parler pour gagner. Sémiotique des discours de la campagne présidentielle de 2007. París: Presses de la FNSP.

Bucher, G. (1997). «De la perfection de la théorie à l'imperfection des lettres», en Landowski et al. Lire Greimas. Limoges: Pulim.

Calame, Cl. (ed.) (1988). La lettre. Friburgo: Éditions Universitaire de Friburg.

FLoch, J.-M. (1986). Les formes de l'empreinte. Périgueux: Fanlac.
Fontanille, J. y Cl. Zilberberg (1998). Tension et signification. Lieja: Mardaga. [En español: Tensión y significación. Lima: Universidad de Lima, Fondo Editorial, 2004].

GeninascA, J. (1997). "Et maintenant", en Landowski, Eric et al. Lire Greimas. Limoges: Pulim.

—. (1984). "Le regard esthétique". Actes Sémiotiques-Documents VI, 58. También en La parole littéraire. París: PUF, 1997. [En español: “El habla literaria". Documento de trabajo. Lima: Universidad de Lima, Facultad de Comunicación, 2011].

Greimas, A. J. (2000). La mode en 1830: Langage et société. París: PUF (1966). Sémantique structurale. París: Larousse. [En español: Semántica estructural. Madrid: Gredos, 1971].

- (1987). De la imperfection. Périgueux: Fanlac. [En español: De la imperfección. México-Puebla: Fondo de Cultura Económica/BUAP, 1990].

—. (1984). "Semiotique figurative et semiotique plastique". Actes Semiotiques, VI, 60. [En español: "Semiótica figurativa y semiótica plástica", en Hernández Aguilar, Gabriel (ed.). Figuras y estrategias. México: Siglo XXI, 1994].

Greimas, A. J. y J. Fontanille (1991). Sémiotique des passions. París: Seuil. [En español: Semiótica de las pasiones. México: Siglo XXI- BUAP, 1994].

Greimas, A. J. y E. Landowski (1979). Introduction à l'analyse du discours en sciences sociales. París: Hachette. 
Greimas, A. J. y J. Courtés (1979). Sémiotique. Dictionnaire raisonné de la théorie du langage. París: Hachette. [En español: Semiótica. Diccionario razonado de la teoría del lenguaje, tomo I. Madrid: Gredos, 1982].

Hénault, A. (1994). Le pouvoir comme passion. París: PUF.

Hernández Aguilar, Gabriel (1994). Figuras y estrategias: en torno a una semiótica audiovisual. México: Siglo XXI.

Jullien, Fr. (1996). Traité de l'efficacité. París: Gallimard.

Kersyté, N. (2009). “La sémiotique d'A. J. Greimas entre logocentrisme et pensée phénomé-nologique". Nouveaux Actes Sémiotiques. <http:// revues.unilim.fr/nas $>112$.

LANDOWsKI, E. (2008). "La politiquespectacle revisitée: manipuler par contagion". Versus 107.

_. (2007a). Presencias del otro. Ensayos de socio-semiótica II. Lima: Universidad de Lima, Fondo Editorial.

_. (2007b). "Le triangle publicitaire", en Semiótica 163.

—_. (2007c). "Unità del senso, pluralità di regimi", en Marrone, Gianfranco y Nicola Dusi (eds.). Narrazione ed esperienza. Intorno a una semiótica della vita cuotidiana. Roma: Meltemi.

—. (2006). "L'épreuve de l'autre". Sign Systems Studies 34, 2.

—. (2005). Les interactions risquées. Limoges: Pulim. [En español: Interacciones arriesgadas. Lima: Uni- versidad de Lima, Fondo Editorial, 2009b].

- (2004). Passions sans nom. Essais de socio-sémiotique III. París: PUF. [En español: Pasiones sin nombre. Lima: Universidad de Lima, Facultad de Comunicación, 2009a -Prepublicación-Circulación interna].

—. (1997a). "Le sémioticien et son double", en Landowski, Eric. Lire Greimas. Limoges: Pulim.

—_. (1997b). Présences de l'autre. Essais de socio-sémiotique II. París: PUF. [En español: Presencias del otro. Ensayos de socio-semiótica II. Lima: Universidad de Lima, Fondo Editorial, 2007].

—. (1989). La société réfléchie. Essais de socio-sémiotiques I. París: Seuil. [En español: La sociedad figurada. México: Fondo de Cultura Económica, 1993].

—. (1988). "La lettre comme acte de présence", en $\mathrm{Cl}$. Calame. La lettre. Fribourg: Editions Universitaires de Fribourg.

LANDOWski, E. et al. (1997). Lire Greimas. Limoges: Pulim.

Lévi-Strauss, Cl. (1955). Tristes tropiques. París: Plon. [En español: Tristes trópicos. Buenos Aires: Eudeba, 1970].

Marrone, Gianfranco y Nicola Dusi (eds.) (2007). Narrazione ed esperienza. Intorno a una semiótica della vita cuotidiana. Roma: Meltemi. 
Merleau-Ponty, M. (1945). Phénoménologiedelaperception. París:Gallimard. [En español: Fenomenología de la percepción. Barcelona: Ediciones Península, 1975].

Parret, H. (2001). "Présences". Nouveaux Actes Sémiotiques 76. [En español: en Epifanías de la presencia. Ensayos semio-estéticos. Lima: Universidad de Lima, Fondo Editorial, 2008].

SARTre, J.-P. (1947). L'être et le néant. París: Gallimard. [En español:
El ser y la nada. Madrid: Alianza Editorial, 1984].

Tarasti, E. (2009). Fondements de la sémiotique existentielle. París: L'Harmattan.

- (2000). Existencial Semiotics. Bloomington: Indiana University Press.

Traducción: Desiderio Blanco Título original: Une Sémiotique à refaire? 